This document was prepared in conjunction with work accomplished under Contract No. DE-AC09-96SR18500 with the U.S. Department of Energy.

This work was prepared under an agreement with and funded by the U.S. Government. Neither the U. S. Government or its employees, nor any of its contractors, subcontractors or their employees, makes any express or implied: 1 . warranty or assumes any legal liability for the accuracy, completeness, or for the use or results of such use of any information, product, or process disclosed; or 2 . representation that such use or results of such use would not infringe privately owned rights; or 3 . endorsement or recommendation of any specifically identified commercial product, process, or service. Any views and opinions of authors expressed in this work do not necessarily state or reflect those of the United States Government, or its contractors, or subcontractors. 


\section{EVALUATION OF THE FAILURE OF A RADIOACTIVE WASTE TRANSFER LINE JACKET}

\author{
Bruce J. Wiersma \\ Savannah River National Laboratory \\ Washington Savannah River Company \\ Savannah River Site \\ Aiken, SC, 29808 \\ USA \\ Charles F. Jenkins \\ Savannah River National Laboratory \\ Washington Savannah River Company \\ Savannah River Site \\ Aiken, SC, 29808 \\ USA
}

\author{
Karthik H. Subramanian \\ Savannah River National Laboratory \\ Washington Savannah River Company \\ Savannah River Site \\ Aiken, SC, 29808 \\ USA \\ William R. Hinz \\ Savannah River National Laboratory \\ Washington Savannah River Company \\ Savannah River Site \\ Aiken, SC, 29808 \\ USA
}

\author{
A. Scott Plummer \\ Washington Savannah River Company \\ Savannah River Site \\ Aiken, SC, 29808 \\ USA \\ Andrew P. Fellinger \\ Savannah River National Laboratory \\ Washington Savannah River Company \\ Savannah River Site \\ Aiken, SC, 29808 \\ USA
}

\section{ABSTRACT}

Radioactive wastes are confined in 49 underground storage tanks at the Savannah River Site. The waste is transported between tanks primarily via an underground transfer piping system. Due to the hazardous nature of the waste, the inner core stainless steel pipe is typically surrounded by a carbon steel pipe jacket, which provides secondary containment. Recently several through-wall penetrations were discovered on a segment of one of the jackets. An evaluation was performed to verify the failure mechanism and to estimate the degree of damage that occurred to the pipe segment. Failure analysis of a section of the jacket confirmed that pitting corrosion on the exterior of the pipe led to the through-wall penetration. Ultrasonic measurements on sections of the pipe were utilized to determine the remaining wall thickness in adjacent areas of the pipe. Based on these measurements, the degree of pitting and general corrosion was determined. Pit growth rate models were then developed to estimate the life expectancy of sections of the pipe that had not been excavated. The calculations estimated that the occurrence of through-wall failures in this jacket will begin to increase substantially in 12 years. Given that this pipe segment will be utilized beyond this time, shortterm and long-term solutions to this failure were proposed. The short-term solutions focused on the repair or replace decisions that must be made to return the jacket to service as soon as practical. The long-term solutions focused on a broader strategy to address jacket integrity issues in the entire tank farm facility. These solutions included the evaluation of innovative remote inspection and repair techniques.

\section{INTRODUCTION}

The Savannah River Site (SRS) has been involved in the production of radioactive materials for over 50 years. A byproduct of this process is over 35 million gallons of radioactive waste. The waste is currently stored on an interim basis in 49 underground carbon steel waste tanks on two tank farms. In order to transfer the waste between the tanks, the two tank farms, and other facilities (e.g., the production and vitrification facilities) an intricate system of underground and aboveground piping has been placed. The piping is heavily shielded to minimize worker exposure to radiation.

Recently the failure of an annual pressure test indicated the presence of a through-wall penetration in a transfer line jacket. The jacket penetrations were located with a helium leak tests and repaired. However, the transfer line jacket failed the subsequent pressure test and three additional through-wall penetrations were identified. The following steps were utilized to assess the failures:

a) Review of transfer line piping design and service exposure;

b) Destructive examination of failed section of pipe;

c) Non-destructive examination of the remaining pipe; 
d) A Fitness-For-Service evaluation of the pipe;

e) Recommendations for other inspection and repair techniques.

\section{BACKGROUND ON THE TRANSFER LINE PIPING}

A cut-away drawing of the most common pipe design for the SRS transfer system is shown in Figure 1. The core pipe is typically made of $304 \mathrm{~L}$ stainless steel. The sizes of the core piping range between 1-3 inches in diameter. Core piping that was installed prior to 1988 was Schedule 40 wall thickness, while since then Schedule 10 has been allowed. The piping was designed according to ASME B31.3. The design pressure for the piping was $150 \mathrm{psig}$, although the operating pressure for the line is typically in the 100 psig range.

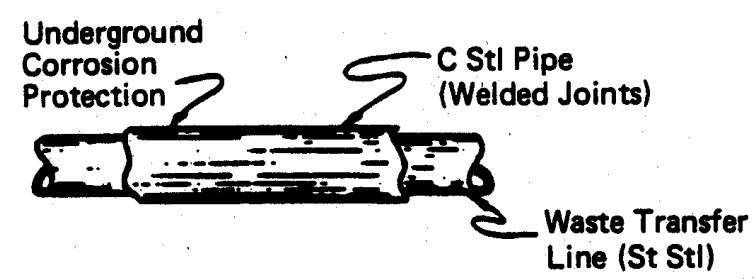

Figure 1. Cut-away drawing of SRS waste transfer line system.

The jacket pipe is constructed of carbon steel. The size of the jacket piping usually depends on the number of core pipes that are contained (between 1 and 3) within. Thus the pipe diameter may range from 4 to 10 inches. Schedule 20 or Schedule 40 piping was typically utilized.

The outside of the jacket piping is usually protected by one of several coating methods: a fusion bonded powder coating system, a coal-tar system, a polyethylene coating, a polyethylene tape, or a bitumastic coating. The thickness of the outer protection for the jacket depended on the type of coating utilized.

Loose granular or powdered thermal insulation was also placed around the coated carbon steel jackets. The layer of thermal insulation was 6 to 8 inches in depth. In general, the insulation materials are hydrophobic and thus prevent water penetration. Therefore, if the insulation was properly placed and the temperature near the insulation has been relatively low, minimal corrosion of the exterior of the steel jacket is expected.

\section{DESTRUCTIVE EXAMINATION OF TRANSFER LINE JACKET SECTION}

Multiple leak sites were observed on the transfer line jacket. The first leak site was discovered in a 1" vent line welded to the jacket. The vent pipe was in the soil backfill and not in the thermal insulation. Two other leak sites were found directly on the jacket. Figure 2 shows two approximately 1 inch diameter holes on the top side of the pipe near the 12 o'clock position. The corrosion appeared to be primarily between the 10 o'clock and 2 o'clock positions on the pipe. The remainder of the pipe appeared to be in good condition, with little or no corrosion. The fourth leak site occurred near a weld joining a 10 " to 8 " reducer pipe to the 8 " jacket. The flaw appeared to be linear probably due to improper welding and inspection during the original installation rather than corrosion. In fact, a linear defect is not likely to have developed from corrosion at this particular location.

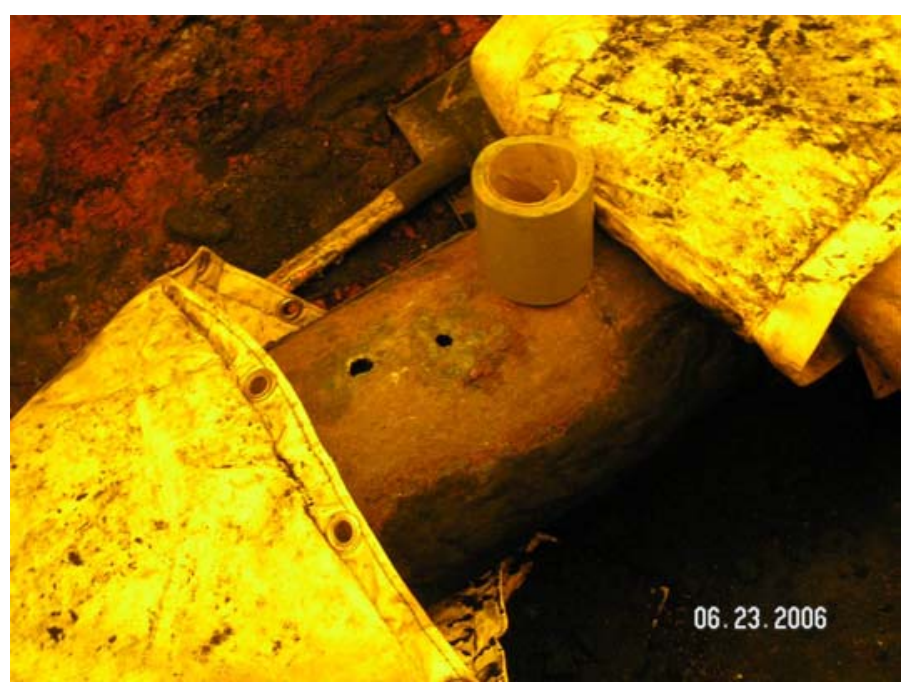

Figure 2. Leak site on transfer line jacket.

A sample of the jacket was core drilled from near one of the leak sites shown in Figure 2. A visual examination of the sample was performed. The disk sample was approximately 0.75 inches in diameter and had been cut such that a throughwall pit was on the outer edge. Figure 3 shows the area near the pit exhibited gradual thinning to the edge, which gave the surface a convex or "dished" shaped appearance. In addition to this pit, there was also evidence of broad, shallow pitting on the exterior surface of the pipe. Some pits had coalesced to yield a rough surface appearance. The depth of these partial throughwall pits was not measured. Neither the coating nor thermal insulation adhered to the sample. 


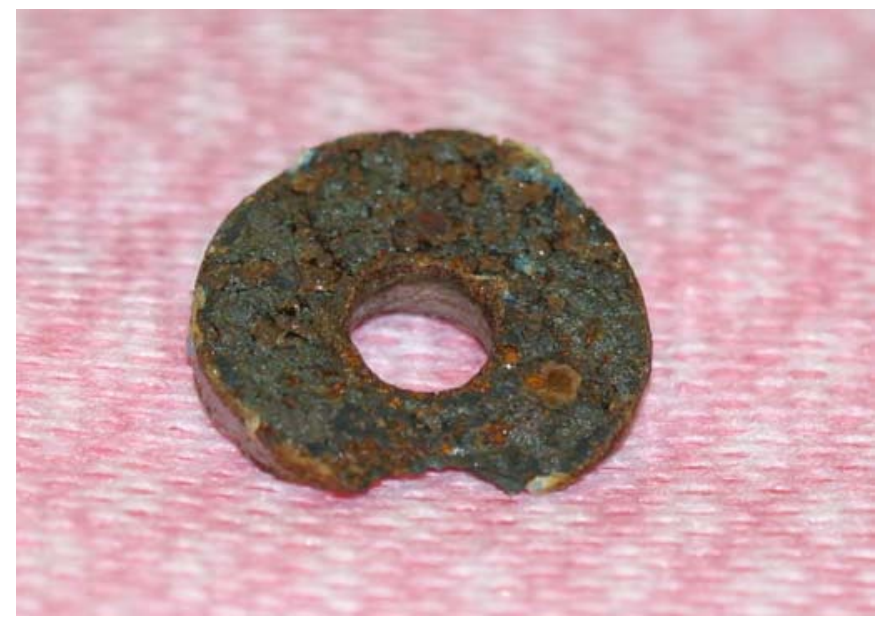

Figure 3. Exterior of cored sample of pipe.

Properly applied coal tar and coal tar epoxy coatings provide excellent corrosion protection. However, small defects (i.e., holidays) occasionally remain in the coating after application is complete. Defects in coatings may also occur during backfilling as rocks and equipment may scrape the pipe surface. These defects provide an ideal site for corrosion to occur should water penetrate to the surface. The thermal insulation is hydrophobic and if it has been properly placed will effectively prevent water intrusion. However, this particular thermal insulation has been known to sinter and crack if it is exposed to temperatures greater than $325^{\circ} \mathrm{F}$. The cracks allow water to penetrate through the insulation to the steel surface. The thermal insulation also contains organic compounds that break-down at the higher temperatures. The result is that the acidity of the liquid that eventually becomes trapped between the insulation and the pipe may be as low as $\mathrm{pH} 2$. Accelerated corrosion in this acidic environment will likely occur at any coating defect.

The risk of the thermal insulation being exposed to high temperature was reviewed. Steam lines were constructed about the same time as the transfer lines and were also placed in a trench and covered with the thermal insulation. The distance between the steam lines and the transfer lines is approximately 1 foot for a majority of the transfer pipe path.

Failures of steam lines that were buried in this thermal insulation are quite common. The average time to failure of a steam system line has been approximately 18 years, although failures have been observed at as low as 6 years of service. The steam lines in this area transport 25\# steam (saturated steam temperature $240{ }^{\circ} \mathrm{F}$ ) and $150 \#$ steam (saturated steam temperature $358{ }^{\circ} \mathrm{F}$ ). All four leak sites are located near a failure of a steam condensate line. This failure occurred in 1991. These failures could provide not only the temperature that might degrade the thermal insulation, but the water necessary for corrosion. Failures of other underground lines in the vicinity have been reported (e.g., domestic water lines). Leaks from these lines would have the effect of keeping the ground saturated with water.

The failure of the vent pipe likely occurred due to galvanic corrosion. As was noted previously, the jacket pipe was buried in the thermal insulation, while the vent appeared to be in the clay soil. Dissimilarity in the electrical resistance between the thermal insulation and the soil backfill can create a corrosion macro-cell that can accelerate corrosion in the less resistant soil. In this case, the soil has a lower electrical resistance than the insulation and the vent pipe corroded preferentially. Defects in the coating on the vent pipe would also contribute to the problem.

The cause of the linear defect at the reducer is less certain as no examination was performed to determine if there was at a preexisting weld defect, if any corrosion had occurred, or if poor backfill/excessive surface overload could have contributed to the pipe bending and then cracking.

\section{ULTRASONIC MEASUREMENTS OF THE TRANSFER LINE JACKET}

Ultrasonic testing (UT) is a nondestructive test applied to elastic sound-conductive materials to locate non-homogeneous structural discontinuities. UT has proven effective in detecting service induced flaws such as pitting, cracks, or general corrosion in SRS equipment. The UT results will provide the most accurate information on the condition of the inner and outer pipe walls. Typically UT is performed on the outer pipe wall at an excavated site.

Data analysis is facilitated if the UT data is presented in the form of a wall thickness map showing the location and depth of the pits (see Figure 4). It is desirable to minimize the distance between UT wall thickness measurements in order to characterize the morphology of the pit as well as possible. An example is presented to illustrate the determination of a pit depth and the average depth of penetration due to general corrosion. To determine the maximum pit depth in a given area, the minimum wall thickness is located. Figure 5 shows a $3 \times 3$ square inch grid with the minimum wall thickness located in the center. The average of the eight other wall thicknesses measurements is determined next. The pit depth is then calculated by subtracting the minimum wall thickness from this average wall thickness. The ASTM guidelines for pit evaluation recommend that a minimum of 10 pits be utilized to describe the metal penetration due to pitting [1]. 


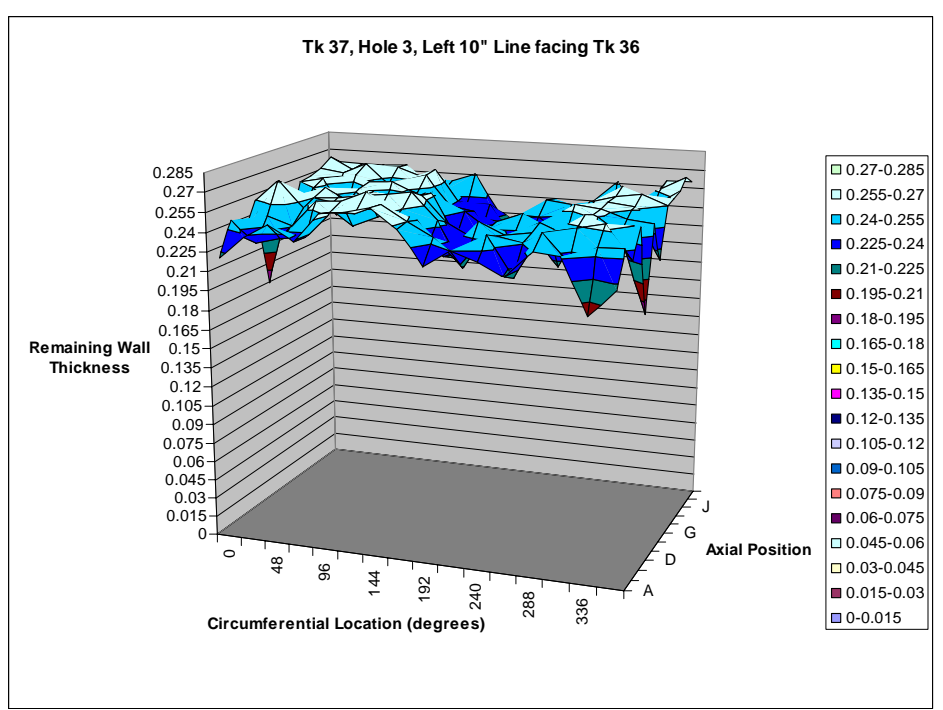

Figure 4: Wall Thickness Map Showing the Location and Depth of Pits

In order to determine the depth of penetration due to general corrosion, the initial wall thickness must be determined. There are two candidates for the initial wall thickness: a) the nominal wall thickness of 0.25 " and b) the maximum wall thickness measured by the UT data. The wall thickness of the pipe is variable and can be as much as $10 \%$ less than the nominal value per ASTM A320 [2]. Therefore rather than use the maximum wall thickness, the nominal thickness is probably more representative of an average initial wall thickness. Therefore the initial wall thickness will be assumed to be 0.25 ". The average of the eight wall thicknesses can be defined as the penetration due to general corrosion that has occurred in this local area. As mentioned previously, a minimum of 10 determinations will characterize the depth of penetration adequately. The average of the 10 or more determinations of penetration due to general corrosion is calculated. This average is subtracted from the nominal wall thickness to determine the depth of penetration due to general corrosion.

\begin{tabular}{|l|l|l|}
\hline 0.237 & 0.254 & 0.271 \\
\hline 0.244 & 0.185 & 0.255 \\
\hline 0.251 & 0.249 & 0.235 \\
\hline
\end{tabular}

Figure 5: 3 x 3 square inch Grid of Wall Thickness Measurements Where the Center is the Minimum, i.e. Pit Bottom
Wall thickness mapping was performed at three locations along the transfer line jacket. Each segment was one foot long. However, due to scale and deposits on the surface, regions of the segment in two of the three cases could not be inspected. In order to obtain more than 10 maximum pit depths (i.e., more than 10 sampling areas), each foot long segment was divided into four three inch long segments. The maximum pit depth, penetration due to general corrosion, and total penetration were calculated for the twelve pipe segments.

The location of the deepest penetration in relation to the circumference of the pipe is summarized in Table 1. Figure 6 also shows a wall thickness contour plot that illustrates where corrosion is occurring on the pipe. The areas within $\pm 40^{\circ}$ of top dead center (TDC) and bottom dead center (BDC) underwent the most significant corrosion (i.e., deepest penetration). In the situations where the deepest pits were not located near TDC or BDC, no UT data was collected due to heavy scale and deposits at BDC. Both TDC and BDC are located at horizontal tangents to the pipe, which is the most likely place for water to accumulate beneath the thermal insulation. Thus, it is not surprising that the most aggressive corrosion occurs in these regions.

\section{Table 1: Summary of UT Thickness Measurements}

\begin{tabular}{|l|c|c|c|c|}
\hline Area ID & $\begin{array}{l}\text { Penetration Due to } \\
\text { General Corrosion (mils) }\end{array}$ & $\begin{array}{l}\text { Maximum Pit } \\
\text { Depth (mils) }\end{array}$ & Total Penetration (mils) & $\begin{array}{c}\text { Location of } \\
\text { Deepest Pit }^{\mathrm{b}}\end{array}$ \\
\hline $37-1-1$ & 12 & 84 & 96 & 0 \\
\hline $37-1-2$ & 6 & 27 & 33 & 327 \\
\hline $37-1-3$ & 20 & 31 & 51 & $98^{\mathrm{c}}$ \\
\hline $37-1-4$ & 11 & 61 & 72 & $98^{\mathrm{c}}$ \\
\hline Average & 12.25 & 50.75 & 63 & \\
\hline Maximum & 20 & 84 & 96 & 0 \\
\hline \hline $37-3-1$ & 12 & 37 & 49 & 336 \\
\hline $37-3-2$ & 1 & 65 & 66 & 192 \\
\hline $37-3-3$ & 23 & 21 & 44 & 216 \\
\hline $37-3-4$ & 22 & 28 & 50 & \\
\hline Average & 14.5 & 37.75 & 52.25 & 144 \\
\hline Maximum & 22 & 65 & 66 & $96^{\mathrm{c}}$ \\
\hline $36-3-1$ & 36 & 10 & 46 & 144 \\
\hline $36-3-2$ & 27 & 32 & 59 & $120^{\mathrm{c}}$ \\
\hline $36-3-3$ & 30 & 62 & 92 & \\
\hline $36-3-4$ & 35 & 27 & 62 & \\
\hline Average & 32 & 32.75 & 64.75 & \\
\hline Maximum & 36 & 62 & 92 & \\
\hline \hline Total & & & & \\
\hline Average & 19.6 & 40.4 & 60.0 & \\
\hline Maximum & 36 & 84 & 96 & \\
\hline
\end{tabular}

$\mathrm{a}$ - Area ID is designated as $\mathrm{xx}-\mathrm{y}-\mathrm{z} ; \mathrm{xx}=$ tank from which the jacket originated; $y=$ the excavation hole designation; $z=$ three inch sample segment.

$\mathrm{b}$ - Location is expressed in degrees in the clockwise direction from top dead center.

c - Wall thickness at bottom dead center of pipe was not determined.

The general corrosion and pitting data shown in Table 1 also indicates that all three locations experienced a similar degree of corrosion. For example, each location had a maximum pit depth greater than 60 mils. The amount of general corrosion appeared to be slightly higher on the pipe that was coming 
from an adjacent waste tank. However, this could be an indication of a high pit density, where many smaller pits have coalesced together to give a roughly uniform corrosion appearance. The total penetration due to general corrosion and pitting ranged between 52 to 65 mils for the three locations. The consistency between these values is probably the best indicator that the degree of corrosion was similar.

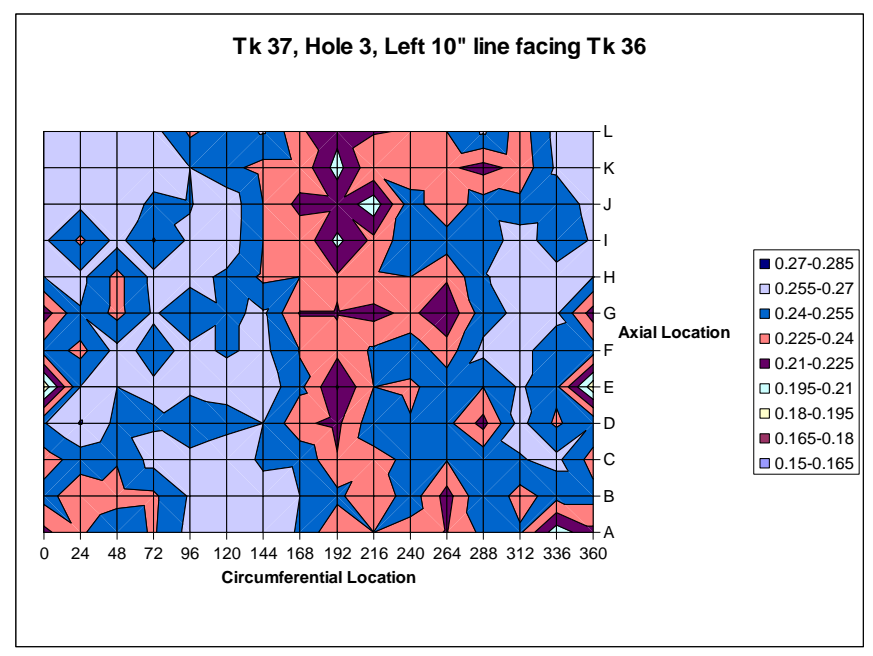

Figure 6: Contour Map Showing Areas of Most Prevalent Corrosion

\section{FITNESS-FOR-SERVICE EVALUATION}

\section{Estimation of Remaining Service Life}

Pitting is characterized by localized intense corrosion of the metal, while the majority of the surface remains unattacked. Pits come in various shapes and sizes depending upon the material and the environment. The pit morphology for carbon steel in aqueous environments tends to be broad and shallow. Frequently the pits coalesce and give the surface a localized general corrosion appearance. Thus differentiating between general attack and pitting is at times difficult. Nevertheless, the maximum pit depth and the average penetration due to general corrosion were assessed.

The observation of pitting in one section of the pipe raises the concern that through-wall pits may have developed at some other location along the pipe that had not been excavated. The National Bureau of Standards performed corrosion tests that investigated the relationship between the size of the structure under study and the deepest pits observed [3]. It was concluded that the depth of the deepest pit, $\mathrm{P}_{\mathrm{d}}$, increases with area, $\mathrm{A}$, according to

$$
\mathrm{P}_{\mathrm{d}}=\mathrm{bA}^{\mathrm{c}}
$$

where $\mathrm{b}$ and $\mathrm{c}$ are constants. The larger the area that is inspected, the more likely you are to find the deepest pit. Therefore, a technique is needed that can be used to extrapolate the deepest pit measured from a small section of the pipe to the deepest pit that exists on the pipe.

Pitting is a random process due to changes in the local environmental conditions that affect pit initiation, growth, and repassivation processes. As a result, the pit depths conform to a statistical distribution. It is usually not possible to determine the underlying distribution of all pits because of the difficulty in measuring the smallest pits. However, from the standpoint of failure of the pipe the few deepest pits are of much greater concern than the many shallower pits.

The statistics of extreme values have been found useful in analyzing and characterizing the distribution of deepest pits at a given time. The technique may be utilized to predict the deepest penetration due to pitting on the whole transfer line based on a limited number of measurements on a small section of the pipe. This technique has been applied to pitting on steel pipelines [4] and pitting at the liquid-air interface in high level radioactive waste tanks [5]. An ASTM standard provides guidance for evaluating the results of ultrasonic measurements of pit depths using this statistical technique [1].

The type 1, or exponential, distribution has been utilized to describe the maximum pit depth measurements [6]. The form of this distribution is the double exponential

$$
F(x)=\exp \left(-e^{-y}\right)
$$

with the reduce variate $y$ given by

$$
y=\alpha(x-\mu)
$$

where $y$ lies in the range $-\infty<y<\infty, \mu$ is a parameter defining the location of the distribution, and $\alpha$ a parameter defining the width of the distribution. $\mathrm{F}(\mathrm{x})$ is the probability that any pit measured is shallower than a depth $\mathrm{x}$. Thus, the quantity 1$\mathrm{F}(\mathrm{x})$ is the risk of accepting $\mathrm{x}$ as the deepest possible pit. The unbounded range of this distribution is not a precise physical representation of corrosion mechanisms as it does not model electrochemical limits to pitting that occur due to the solution resistance in a deep pit. Nonetheless, the type 1 distribution has been acknowledged to yield satisfactory results.

The method for analyzing pit depths involves assigning a plotting position on the ordinate for the relevant measured depth on the abscissa. This position is the cumulative frequency of the distribution and is obtained by dividing the rank of the measurement, $m$, by the sum of 1 plus the total number of sections, $\mathrm{N}$, on the pipe that have been measured. The cumulative frequency can be converted to the linear scale of the reduced variate $y$ by a double logarithmic transformation 


$$
y=-\ln [-\ln (m / N+1)]
$$

The transformed cumulative frequency versus the mth deepest pit is then plotted and linear regression is performed. The slope of the plot is $\alpha$ and the intercept is $\mu$. The linear equation can be usefully extrapolated to investigate the likelihood of the deepest pit on a larger surface area. This procedure uses the concept of a return period, $T$. In mathematical terms $T$ is the reciprocal of $1-F(x)$. In physical terms $T$ is the area of pipe that is vulnerable to pitting relative to the area of the section of pipe where the pits were measured. The expected deepest pits converge to

$$
\mathrm{x}=\mu+\ln (\mathrm{T}) / \alpha
$$

for Type 1 extreme value distributions. Inserting the values for $\mathrm{T}$ and the distribution parameters yields the expected deepest pit.

Full penetration of the pipe wall thickness occurs by the combination of general and pitting corrosion. Therefore, Total Penetration, $T_{p}$, can be calculated as follows

$$
\mathrm{T}_{\mathrm{p}}=\text { General Corrosion Depth }+ \text { Maximum Pit Depth }
$$

Metal penetration can be expressed in terms of a pitting factor [1]. The pitting factor (PF) is the ratio of the deepest pit to the depth of general corrosion as shown in the following relationship.

$$
\mathrm{PF}=\text { Maximum Pit Depth/Depth of General Corrosion }
$$

Substitution yields

$$
\begin{gathered}
\mathrm{T}_{\mathrm{p}}=(\text { Maximum pit depth } / \mathrm{PF})+\text { Maximum Pit Depth } \\
\text { or } \\
\mathrm{T}_{\mathrm{p}}=\text { Maximum Pit Depth }(\mathrm{PF}+1 / \mathrm{PF})^{\prime}
\end{gathered}
$$

The kinetics of pit growth are typically described by a power law of the form

$$
\mathrm{P}_{\mathrm{d}}=\mathrm{k} \mathrm{t}_{\mathrm{s}}^{\mathrm{n}}
$$

where $P_{d}$ is the maximum pit depth, $t$ is the time since pitting initiated, $\mathrm{k}$ is a constant dependent upon the material and environment, and $\mathrm{n}$ is a constant [7]. A review of the corrosion databases for long-term pit growth concluded that this empirical relationship provides the best fit to the data [8]. The value of $\mathrm{n}$ for mild steel is typically 0.5 [9]. Therefore,

$$
\mathrm{T}_{\mathrm{p}}=\mathrm{kt}_{\mathrm{s}}^{1 / 2}(\mathrm{PF}+1) / \mathrm{PF}
$$

Re-arrangement of Equation 10 provides an estimate for the time to penetration, $\mathrm{t}_{\mathrm{p}}$,

$$
\mathrm{t}_{\mathrm{p}}=\left[\mathrm{PF} \mathrm{T}_{\mathrm{p}} /(\mathrm{k}(\mathrm{PF}+1))\right]^{2}
$$

The constant $\mathrm{k}$ is determined by rearranging Equation 9

$$
\mathrm{k}=\mathrm{P}_{\mathrm{d}} / \mathrm{t}_{\mathrm{s}}^{1 / 2}
$$

Therefore the final equation for time to penetration in terms of the maximum pit depth measured is

$$
t_{p}=\left[P F T_{p} t_{s}^{1 / 2} / P_{d}(P F+1)\right]^{2}
$$

The time to penetration can be used to predict the expected service life of the transfer line jacket. The variable that will perhaps influence this time the most is $t_{s}$, the number of years since pitting initiated assuming as a basis the year 2006. This time for most transfer lines will be unknown and could vary over a number of years. For example, the pitting on the Tank 37 transfer line could have initiated between 1 and 29 years ago.

The remaining service life, $t_{\mathrm{rs}}$, is the time from 2006 until through-wall pitting is observed and is calculated by:

$$
\mathrm{t}_{\mathrm{rs}}=\mathrm{t}_{\mathrm{p}}-\mathrm{t}_{\mathrm{s}}
$$

The remaining service time provides an estimate for when the degree of through-wall pitting may increase substantially.

The length of the pipe was utilized to determine the return period, $T$, for the maximum pit depth calculation. The total length of pipe was 393 feet. For approximately 384 feet the pipe is 10 " diameter, while for the remaining 9 feet the pipe is 8 " diameter. Thus the total surface area of pipe is $1024 \mathrm{ft}^{2}$. Due to the facts that the pipe diameter was not the same at each of the three locations and surface deposits prevented wall thickness measurements in certain regions, the segments that were defined for the analysis did not have identical surface areas. Therefore an average segment surface area was calculated in the following manner. The surface area of the three sections that were inspected was calculated initially. The area that could not be inspected was calculated and then subtracted from this value to determine the total area inspected. The total area inspected was divided by twelve to represent the number of segments that were analyzed. This technique gives an average segment surface area. The average segment surface area was $0.494 \mathrm{ft}^{2}$. The return period is the total surface area of pipe divided by the average segment surface or approximately 2070.

The deepest pit on a pipe segment $\left(\mathrm{P}_{\mathrm{d}}\right)$, the cumulative frequency and the transformed cumulative frequency are shown in Table 2. The plot of the deepest pit vs. the transformed cumulative frequency is shown in Figure 7. The slope of the line is 0.045 and the intercept is -1.3156 . Substitution of these 
values and the return period calculated previously into Equation 5 give and expected maximum pit depth of 168.3 mils.

The maximum total penetration is the sum of the average wall thinning and the expected maximum pit depth. Table 3 indicates that the average wall thinning was 19.6 mils less than nominal. Therefore, the total penetration is approximately 187.9 mils. Thus based on these UT measurements it is estimated that corrosion has penetrated approximately $75 \%$ through-wall.

Table 2: Summary of Extreme Value Statistics Data

\begin{tabular}{|c|c|c|c|}
\hline Order $\mathrm{m}$ & $\mathrm{m} /(\mathrm{N}+1)$ & $\mathrm{P}_{\mathrm{d}}$ (mils) & $\mathrm{y}$ \\
\hline 1 & 0.077 & 10 & -0.942 \\
\hline 2 & 0.154 & 21 & -0.627 \\
\hline 3 & 0.231 & 27 & -0.383 \\
\hline 4 & 0.308 & 27 & -0.164 \\
\hline 5 & 0.385 & 28 & 0.046 \\
\hline 6 & 0.462 & 31 & 0.257 \\
\hline 7 & 0.538 & 32 & 0.480 \\
\hline 8 & 0.615 & 37 & 0.723 \\
\hline 9 & 0.692 & 61 & 1.000 \\
\hline 10 & 0.769 & 62 & 1.338 \\
\hline 11 & 0.846 & 65 & 1.789 \\
\hline 12 & 0.923 & 84 & 2.525 \\
\hline
\end{tabular}

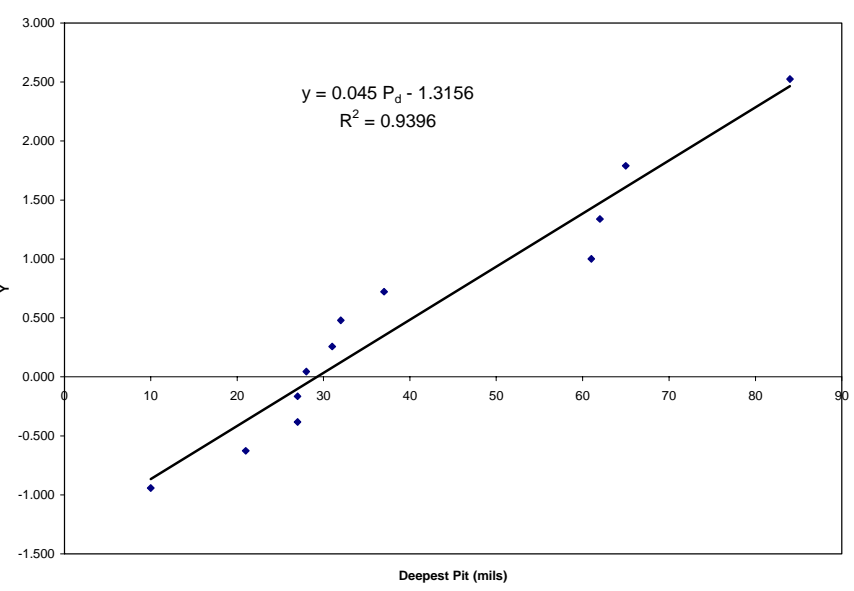

Figure 7: Plot of Deepest Pit vs. Variate 'y'

Equation 13 is utilized to calculate the expected time to penetration. The following inputs were needed.

$\mathrm{P}_{\mathrm{d}}=$ expected maximum pit depth $=168.3$ mils

$\mathrm{T}_{\mathrm{p}}=$ nominal wall thickness $=250 \mathrm{mils}$

$\mathrm{PF}=$ pitting factor $=168.3 \mathrm{mils} / 19.6 \mathrm{mils}=8.59$

$\mathrm{t}_{\mathrm{s}}=$ time at which pitting initiates
The time to through-wall penetration was calculated assuming that the pits initiated in 1991 (i.e., the time at which the steam leak was located). The remaining service life for the remainder of the transfer line jacket was calculated from Equation 14 to be 12 years.

There are two factors which suggest that the majority of the damage has occurred in the last 15 years (i.e., since 1991). Domestic water line and steam line leaks have occurred in this vicinity. Thus the ground around these pipes have been saturated with water since this time. Although repairs have been made to these lines, due to the high radiation levels in the ground, there is no guarantee that all the leaks have been found and repaired. There have also been several excavations in this area. Excavations disturb the soil and possibly the thermal insulation and coating allowing for ingress of water to the pipe and corrosion to occur. Given these two factors, the calculations suggest that there will be a significant increase in through-wall pitting in the next 12 years.

\section{RECOMMENDATIONS FOR INSPECTION AND REPAIR}

Thus far, there have been few in-service inspections of transfer line jacket piping due to the difficulty with excavations and UT testing. However, a specific NDE technique must be developed for long term use in determining the amount of degradation in the jacket piping. It is recommended that several NDE techniques be evaluated and demonstrated. Once demonstrated, the transfer line jackets most likely vulnerable to similar failures can be made part of a routine in-service inspection program. Examples of available NDE techniques are discussed briefly.

\section{Ground Penetrating Radar}

Leaks in underground piping are frequently difficult to locate. During recent efforts to repair steam lines it was necessary to enlarge the initial excavation when no leaks were discovered on the sections of exposed pipe. Therefore, much operating time and maintenance/construction money was lost. New techniques for leak detection are needed to remedy this situation. It is important to note that the primary issues of safety and excavation costs are not eliminated by these techniques. The lines are aging and failures will occur more frequently in the future. The techniques, however, may reduce the amount of unnecessary excavation.

In many cases transfer line jacket failures are associated with steam leakages. The first step in locating a steam leaksite is to inspect the suspected area for sub-surface voids in the soil associated with the leak. A technique known as ground penetrating radar (GPR) may prove useful for the detection of these voids. The technique uses an instrument which emits high frequency radar pulses in order to locate underground 
objects at depths between 6 inches to 40 feet. These objects are distinguished from the soil by differences in the dielectric constants. This method is not effective in locating the steam lines, as the insulation surrounding the lines is transparent to the radar pulses. However, the dielectric constants for air or water associated with a void are significantly different from that of the soil. This procedure coupled with drawings showing steam line locations would indicate the leaksite and pinpoint the area for excavation.

\section{Remote Field Eddy Current (RFEC)}

The Remote Field Eddy Current (RFEC) inspection technique is a nondestructive method which uses low frequency $\mathrm{AC}$ and through wall transmission to inspect pipes and tubes from the inside. The through-wall nature of the technique allows external and internal defects to be detected with approximately equal sensitivity. This technique could be utilized to assess the condition of the jacket pipe within several feet of the leak site. If the pipe contains other defects which are deep or nearly through-wall it is cost effective to extend the excavation and replace the pipe once rather than re-excavating and repeating the process in a few months. This technique has the advantage that the lines can be inspected without the addition of water. The only disadvantage to this technique is that the presence of elbows and supports inside the transfer line jacket may be a limiting factor due to the probe diameters currently available at SRS.

Currently, there are several repair technologies that are under consideration. However, a more remote repair technology that does not include significant excavation can be developed utilizing "trenchless technology" that is implemented through the broader commercial market. "No-dig" rehabilitation of aging pipelines is a growing field for infrastructural use that can potentially be leveraged for transfer line jacket repair.

\section{Current Repair/Replace Technology}

The repair technologies for transfer line jackets currently utilized at SRS include:

- Weld patches of steel over the through-wall pit.

- $\quad$ Place a clamshell to seal off the leak site.

- $\quad$ Re-sleeve transfer lines with a new carbon steel jacket.

- Wrap the jacket with a high strength permanent composite material such as Diamond Wrap ${ }^{\mathrm{TM}}$.

- $\quad$ Remove corroded section of pipe and replace with new section of pipe. This solution is being utilized for the Tank 37 transfer line jacket because the high dose rates in the soil surrounding the transfer line jacket limit time for other repair techniques.
All of these repair/replace technologies have been successfully utilized at SRS. However, each of these technologies requires excavation around the underground pipe. Excavations are time consuming, may expose workers to high radiation dose in underground areas such as those near Tank 37, disturb the soil around adjacent piping, and if poor backfill techniques are utilized, could create other problems. Other issues related to excavations that can create additional problems after the repair is complete include:

- Poor field application of a coating. In some cases pits appear at new defects in the repaired coating. In some cases no repairs to the coating were made before backfilling.

- Poor placement of thermal insulation. If the thermal insulation is not properly tamped down, a path for water to ingress between the insulation and the pipe may develop and result in the same problem.

- Poor backfill techniques. Problems such as improper backfill material (i.e, low density material) or insufficient compaction of the backfill can lead to failures. If there is inadequate support beneath the pipe, a local deflection in the pipe can occur and voids will form along the top and bottom of the pipe. Such voids introduce the possibility of strain instability and buckling.

Given these limitations and the potential for similar pipe failures in the future, evaluation of trenchless or "no-dig" repair/replace technologies for the transfer line jackets is recommended.

\section{“No-Dig” Repair/Replace Technology}

The cost and safety issues associated with traditional transfer line jacket repair technologies are significant. As such, the use of repair technologies that do not involved significant excavation is the preferred alternative when possible. Trenchless technology systems are often used for the installation, replacement and rehabilitation of underground pipes where personnel entry is not possible.

Repair technologies for replacement installations are either horizontal drilling or microtunneling. Horizontal directional drilling is a trenchless surface-launched method for installing relatively small diameter pipes. Microtunneling is used when constructing pipelines where close tolerance for line and grade is required. This method involves using a remote controlled, laser-guided pipe-jacking system for which personnel entry is not required. The process can be used for a range of pipeline diameters.

The rehabilitation of underground pipelines has also been a broad commercial initiative within the last decade. 
Rehabilitation involves the lining of a degraded pipe with an acceptable material of construction. The two most common technologies are the use of cure-in-place pipe (CIPP), fold-andformed pipe (FPP), and sliplining. CIPP involves inserting a lining material composed of a fabric reconstruction tube impregnated with a thermosetting resin into an entry point. After insertion, the liner is exposed to hot circulating water or steam and hardens. FPP involves the insertion of a thermoplastic pipe fed from a spool into an existing pipe followed by hot water or steam until the liner reaches a temperature elevated enough for rounding. After rounding, the installed liner is allowed to cool, producing a snug-fitting liner in the host pie. Sliplining involves the grouting of annular spaces between the existing pipe and any rehabilitation methods. In this case, sliplining may be modified to grout the annular space between the transfer line jacket and the core transfer line.

\section{CONCLUSIONS}

The performance of the waste transfer piping, both the core and jacket pipes, was evaluated. In general, the piping has performed well for over fifty years. The performance of the stainless steel core piping is expected to continue well into the future (i.e., more than 100 years). It is expected that the carbon steel jackets will continue to fail in isolated regions due to either pitting at holidays in a protective coating or corrosion beneath thermal insulation. However, a significant increase in the number of jacket failures (i.e., through-wall penetrations) is not expected to occur for another 30 to 60 years.

\section{ACKNOWLEDGMENTS}

This document was prepared in connection with work accomplished under contract No. DE-AC09-96SR18500 with the U.S. Department of Energy.

\section{REFERENCES}

1. Standard Guide for Examination and Evaluation of Pitting Corrosion, ASTM G 46-94 (re-approved 2005), ASTM International, West Conshohocken, PA.

2. Standard Specification for General Requirements for Rolled Structural Steel Bars, Plates, Shapes, and Sheet Piling, ASTM A6 -05, ASTM International, West Conshohocken, PA.

3. M. Romanoff, Underground Corrosion, National Bureau of Standards Circular 579, April, 1957.

4. H. F. Finley and A. C. Toncre, Materials Protection, Vol. 3, No. 29, 1964.

5. P. E. Zapp, "Pitting Growth Rate in Carbon Steel Exposed to Simulated Radioactive Waste," CORROSION-96, Paper No. 129, NACE International, Houston, TX, 1996.

6. P. M. Aziz, Corrosion, Vol. 13, p. 51t, 1957.

7. Z. Szklarska-Smialowska, Pitting Corrosion of Metals, National Association of Corrosion Engineers, Houston, TX, 1986.

8. R. J. Campana, R. H. Leary, G. H. Reynolds, and H. E. St. John, "Final Report: Technical Assistance on 10CFR60 Corrosion Reliability Monitoring", GA Technologies Document No. GA-C16932, November 1982.

9. M. B. Ives, Proceedings of the $12^{\text {th }}$ International Corrosion Congress, NACE International, Houston, TX, Vol. 3B, p. 2096, 1993. 